\title{
George Leitmann
}

\author{
Mauro Pontani ${ }^{1}$. Jason L. Speyer ${ }^{2}$
}

Received: 11 September 2021 / Accepted: 12 September 2021 / Published online: 31 October 2021

(c) The Author(s), under exclusive licence to Springer Science+Business Media, LLC, part of Springer Nature 2021

George Leitmann is Professor of the Graduate School and Professor Emeritus of Engineering Science at the University of California, Berkeley. In 1944, after graduation from high school, George enlisted in the Army and was to the 286th Combat Engineering Battalion Reconnaissance Squadron. He was in combat from December 1944 to May 1945. He was discharged in May 1946 after serving at the Nuremberg Trials. After graduation from Columbia University in Physics, he worked for seven years at the Naval Ordnance Test Station, China Lake, focusing on rocket dynamics, rocket trajectory optimization and guidance. This led to graduate studies at UC Berkeley and joining the Berkeley faculty in 1957. His over 50-year career at Berkeley has included everything from research and teaching to serving as the first ombudsman in the UC system. At the beginning of his appointment at Berkeley, he began making contributions to variational calculus and optimal control, both in theory and applications, some of which is contained in an introductory text (1967) and two edited volumes (1965 and 1969), later expanded to a basic text (1981). His research into optimization theory took a geometrical approach that was physically appealing and had great theoretically insight. This work was awarded the Goddard aerospace and the flight mechanics awards of the American Institute of Aeronautics and Astronautics. That in turn led to research in dynamical game theory and its applications, which can be found in three books (1966, 1967 and 1974) and numerous edited volumes, and for which he was awarded the first Isaacs Award of the International Society of Dynamic Games. In the early 1970's and extending into the 1990's, his focus research was on a deterministic approach to robust control. In the deterministic approach, when the bound of the uncertainty is given, the constructed control guarantees that the state of the system enters and remains within a particular neighborhood of the zero state after a finite interval of time. For linear systems, this result required an important assumption called the matching condition (i.e., the null space of the control coefficient is contained in the null

$凶$ Mauro Pontani

mauro.pontani@uniroma1.it

1 Department of Astronautical, Electrical, and Energy Engineering, Sapienza Università di Roma, Rome, Italy

2 Department of Mechanical and Aerospace Engineering, University of California, Los Angeles, CA, USA 
space of the disturbance coefficient) is satisfied, implying the system is controllable in the presence of uncertainty. This approach to uncertainty was a precursor to current robust control methodology based on game theory. These controllers have applications to uncertain systems in engineering, science, economics and management, for which he was awarded the Levy medal of the Franklin Institute. He is a member of the National Academy of Engineering as well as of six foreign academies of science and engineering, and he holds three honorary doctorates. Since emeritation in 1991, he has returned to earlier work in the calculus of variations, especially numerous extensions of a 1967 paper, which are based on the methodology of equivalent problem solutions and regularizing transformations, which simplify the classical approach of Carathéodory. Professionally, he edited or co-edited over a dozen journals including the largest and arguably the most prestigious journal of mathematical analysis and applications founded by Richard Bellman, the latter as editor for sixteen years. Since Professor Leitmann had many international doctoral students and post-doctoral fellows, he had many international collaborations. One result was that he was awarded an Alexander von Humboldt Prize in 1980, subsequently the A. von Humboldt medal and the Werner Heisenberg medal of the A. von Humboldt Foundation.

Publisher's Note Springer Nature remains neutral with regard to jurisdictional claims in published maps and institutional affiliations. 